\title{
Parents with mood disorders should know the risks for their children
}

\author{
Robert M Post* \\ Clinical Professor of Psychiatry, George Washington University School of Medicine, USA
}

\section{Introduction}

The risks for mood disorders in children in the United States (US) underestimated. Yet they can be readily assessed just on the basis of clinical history. This allows for more careful follow up of those at high risk, and the possibility of early intervention to head off the development of more severe illness. Parental awareness of the risk for their children would allow more systematic assessment of symptoms to facilitate physicians and clinicians evaluating severity of illness and need for treatment. In this manuscript, we detail the ways risk can be preliminarily evaluated and suggest a system for weekly evaluation by parents of a child symptoms in the Child Network. Potential early intervention and prevention strategies are also discussed.

\section{Assessing risk}

Family history of a mood disorder is a potent risk factor for illness in the offspring. In particular, a history of unipolar depression or bipolar disorder in a parent conveys a very substantial risk of a variety of psychiatric difficulties in their offspring. As illustrated in Figure 1, the risk of a lifetime psychiatric diagnosis upon 7 years of follow up in the offspring of a parent with bipolar disorder is an astonishing $74 \%$ [1]. The most common diagnosis are an anxiety disorder and depression, followed by ADHD, disruptive behavioral disorders, substance abuse and bipolar disorder, the latter of which occurs in about $20 \%$ of the children. Strikingly, the offspring of the community control parents (who do not have a diagnosis of bipolar disorder) are also at considerable risk with almost 50\% receiving a psychiatric diagnosis over the 7 years of follow up

The risks of illness in the offspring of a parent with unipolar depression are also high both at 10 years and 20 years of follow up [2] and are in the range of 75 to $80 \%$. The range and order of diagnoses are similar to those seen in the offspring of a bipolar parent (Figure 1, bottom). Again, about $50 \%$ of the offspring of the community controls also had a major psychiatric diagnosis, indicating a high incidence of illness in the general population in the US.

A variety of other clinical factors can be assessed that might further add to the risk of the offspring. If a second generation, i.e., the grandparents, are also ill this further adds to the vulnerability in the offspring of both unipolar and bipolar parents $[3,4]$. Assortative mating (both parents with a mood disorder), which is three times more common in the US compared to the Netherlands and Germany, adds a further bilineal increase in genetic vulnerability [5].

Another added risk factor is adversity in childhood, which interacts with genetic vulnerability to further decrease the age of onset of bipolar disorder [6,7] . Finally, if prodromal symptoms emerge, this adds to the likelihood of the later development of a full-blown syndrome [8].
For example, if a child has a BP not otherwise specified (BP-NOS) diagnosis, they have about a $50 \%$ likelihood of converting to a fullblown diagnosis of BP I or BP II upon several years of follow up if there is a positive family history of bipolar disorder[1]. Another risk factor is if one or both parents' affective illness is not well controlled, and they remain symptomatic, the offspring are more likely to develop psychiatric illness [1,9].

Early onset bipolar disorder is more common in the US than in the Netherlands and Germany (abbreviated here as Europe). Two thirds of the onsets in well-diagnosed adults in the US with bipolar disorder occurred in childhood or adolescence, before age 19, while this was seen in only one third of those from Europe [5]. Early onsets of bipolar disorder are particularly striking when there is a combined high familial loading for psychiatric illness and high degrees of psychosocial stress in childhood [6]. Early onset illness is associated with longer delays to first treatment than adult onset illness, and both early onset and treatment delay are independent risk factors for a poor outcome in adulthood $[10,11]$. An early age of onset of bipolar disorder in a parent also increases risk for the child. The situation in the US is not improving, as there is a cohort effect for an earlier age of onset and increased incidence of both childhood depression and bipolar disorder [12-14].

Preliminary assessment of risk can thus be estimated from the clinical history alone, allowing greater vigilance, and possibly earlier intervention. The assessment of increased risk noted above includes four major variables:

I. Genetics: Illness in one or both parents, and one or both grandparents.

II. Environment: The extent to which parental illness is not well controlled and remission is not achieved.

III. Stressors: The occurrence of childhood adversity, such as abuse, neglect, bullying, etc.

IV. The emergence of prodromal symptoms and syndromes in the child.

In summary, the magnitude of genetic vulnerability alone puts the child at high risk for a variety of psychiatric illnesses of childhood and adolescence. If other environmental factors and stresses have occurred this further increase risk. If these factors are accompanied by the

Correspondence to: Robert M. Post, Clinical Professor of Psychiatry, George Washington University School of Medicine, USA, E-mail: robert.post@ speakeasy.net

Received: November 21, 2017; Accepted: December 12, 2017; Published: December 15, 2017 
High Incidence of Illness in Offspring of a Parent with a Mood Disorder
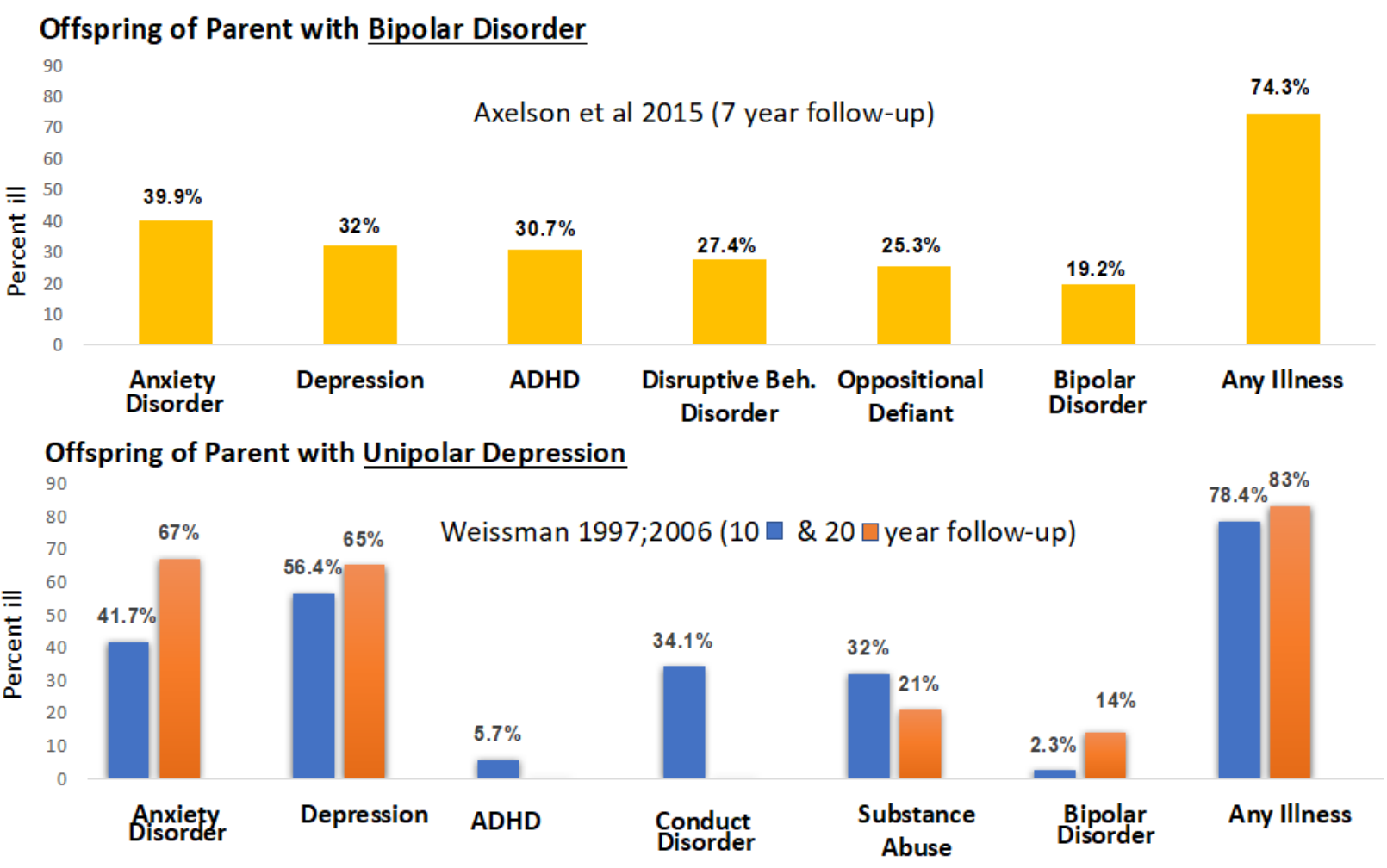

Figure 1. High incidence of illness in offspring of a parent with a mood disorder

additional emergence of prodromal symptoms and syndromes, one might then consider the child a very high risk.

\section{Encouraging longitudinal assessment in those at high risk}

Merikangas et al. [15] found a $2.2 \%$ incidence of bipolar spectrum disorders in adolescents age 13-15, but tragically only about $20 \%$ were in any kind of treatment. If parents are aware of the familial risks for their child, they may be in a better position to urge evaluation and treatment if needed. The majority of children with psychiatric illnesses in the US are seen by primary care physicians [16] who may not be well versed in assessment and treatment.

Parents can assist physicians and clinicians in the evaluation of their child (aged 2 to 12) by providing a detailed longitudinal assessment of symptoms. This can be done, by rating on a weekly basis the severity of symptoms of depression, anxiety, ADHD, oppositional behavior and mania on a secure website available at www.bipolarnews (click on Child Network). These ratings can then be printed out and taken to a clinician for more accurate assessment of symptom course, complexity and severity, and need for intervention or referral [17]. The ratings have the advantage of touching on the most common symptom areas that are present in most of the psychiatric difficulties of childhood.

Pediatricians and primary care physicians have been urged to be the guardians of children's mental as well as physical health [18]. In this regard, they can suggest that parents help in the assessment of a child's psychiatric illness by joining the Child Network. Conversely, psychiatrists who treat adult patients with mood disorder can inquire about the health of their patients' children and, again, encourage their participation in the Child Network.

\section{Potential interventions and prophylaxis}

There are many safe interventions that might be considered for those at high and very high risk [8]. These could include those amenable for primary prevention, i.e., before symptoms develop. Such efforts could include the institution of: a good diet (rich in omega 3 fatty acids); regular sleep and exercise regimens; and mindfulness or meditation training. Hudziak and Albaugh [19] suggest that these be made available to all children universally, and other elements can be added such as playing a musical instrument and joining a sports team (independent of a child's physical abilities). If the child is at very high risk, increased intensity of these and other efforts can then be added.

If prodromal symptoms develop, a wealth of data support the utility of family focused therapy (FFT) or a similar therapy that deals with psychoeducation, enhancing family communication, and developing problem solving skills [20]. In children with a positive family history of bipolar disorder who had depression, cyclothymia, or BP NOS, Miklowitz et al. [21] showed superior outcomes on depression and functioning with FFT compared to control treatment as usual. This would represent secondary prevention or the attempt to deter development of more severe illness.

If full-blown illnesses develop, the Child Network ratings would be particularly useful, since pharmacological and psychotherapeutic treatments are also listed on the printouts, such that treatment effectiveness or need for treatment revision can easily be visualized. Such a graphic of the weekly ratings and treatments is illustrated in Post et al [22] and is accompanied by an in depth discussion of what treatments might lead to more effective symptom resolution than those already utilized in a difficult to treat child. 


\section{Clinical and public health implications}

This longitudinal assessment of symptoms and evaluation of treatment effectiveness for a given child is crucial developing an effective regimen, especially since there are virtually no FDA-approved treatments for children under 10 years of age (with the exception of the psychomotor stimulants and related treatments for ADHD). Thus an individual child's response or non-response trumps any guidelines available from the sparse treatment literature on bipolar I disorder or the guidelines for symptomatic children that are typically based on expert opinion and not systematic clinical trials [23].

This neglect of clinical treatment studies is an additional reason for treatment delay and inadequate treatment in the community [24], and it is important for physicians, parents, and advocacy group members to encourage the NIMH toward a new round of studies on the most effective and best tolerated treatments in young children [25]. A new clinical, research, and public health agenda is needed to begin to address the multigenerational increased risk of psychiatric illness over 4 generations of those emanating from the US compared to Europe [5]. Multiple safe medications could be studied for attempts of secondary and tertiary prophylaxis, including omega-3-fatty acids, $\mathrm{N}$-acetylcysteine, minocycline and other anti-inflammatories, Vitamin D3, folate, and combinations of vitamins and minerals such as those in EM Power.

When children develop a full-blown bipolar disorder, the wide range of medications including lithium, anticonvulsant mood stabilizers, and the atypical antipsychotics that have shown efficacy in adults $[4,26]$ need to be better evaluated for effectiveness and tolerability in these youngsters [27]. This would represent tertiary prophylaxis or prevention of episode recurrence. When youngsters after a first hospitalization for mania are randomized to 2 years of comprehensive expert treatment compared to treatment as usual, there is a marked reduction in the rate of re-hospitalization over these 2 years and difference further grows in magnitude over the next 6 years [28]. This clearly indicates that early, comprehensive treatment can change the long-term course of bipolar disorder. Kozicky et al. [29] and Yatham [30] indicate that after a first episode of mania, brain abnormalities and cognitive deficits recover only if there are no further episodes of illness experienced in the first year. Berk et al. [31] randomized patients with a first mania to 1 year of either lithium or quetiapine and found that lithium was superior to quetiapine on virtually all measures. Taken together, these data emphasize the crucial importance of beginning careful, consistent, and comprehensive pharmacoprophylaxis after a first mania.

A clinical trials network in practice settings would do much to help facilitate the more rapid accumulation of acute treatment data in easyto-perform practical clinical trials, as well as those from all three types of prophylaxis studies [25]. Without the rapid generation of a new round of data on optimal treatments for children, many more generations [4] will continue to suffer from delayed or inadequate treatment along with illness progression from sensitization to the recurrence of stressors, episodes of illness, and bouts of substance abuse [32] and the associated long term adverse consequences to psychiatric and physical health.

\section{References}

1. Axelson D, Goldstein B, Goldstein T, Monk K, Yu H, et al. (2015 ) Diagnostic Precursors to Bipolar Disorder in Offspring of Parents With Bipolar Disorder: A Longitudinal Study. Am J Psychiatry 172: 638-646. [Crossref]

2. Weissman MM, Wickramaratne P, Nomura Y, Warner V, Pilowsky D, et al. (2006) Offspring of depressed parents: 20 years later. Am J Psychiatry 163: 1001-1008. [Crossref]
3. Weissman MM, Wickramaratne P, Nomura Y, Warner V, Verdeli H, et al. (2005) Families at high and low risk for depression: a 3-generation study. Arch Gen Psychiatry 62: 29-36. [Crossref]

4. Post RM, Altshuler LL, Kupka R, McElroy SL, Frye MA, et al. (2016) Age of Onset of Bipolar Disorder Related to Parental and Grandparental Illness Burden. J Clin Psychiatry 77: 1309-1315 [Crossref]

5. Post RM, Altshuler LL, Kupka R, McElroy SL, Frye MA, et al. (2017) More childhood onset bipolar disorder in the United States than Canada or Europe: Implications for treatment and prevention. Neurosci Biobehav 74: 204-213. [Crossref]

6. Post RM, Altshuler LL, Kupka R, McElroy SL, Frye MA, et al. (2016) Age of onse of bipolar disorder: Combined effect of childhood adversity and familial loading of psychiatric disorders. J Psychiatr Res 81: 63-70. [Crossref]

7. Post RM, Altshuler LL, Leverich G, Nolen W, Kupka R, et al. (2013) More stressors prior to and during the course of bipolar illness in patients from the United States compared with the Netherlands and Germany. Psychiatry Res 210: 880-886. [Crossref]

8. Post RM, Chang K, Frye MA, (2013) Paradigm shift: preliminary clinical categorization of ultrahigh risk for childhood bipolar disorder to facilitate studies on prevention. $J$ Clin Psychiatry 74: 167-169. [Crossref]

9. Wickramaratne P, Gameroff MJ, Pilowsky DJ, Hughes CW, Garber J, et al. (2011) Children of depressed mothers 1 year after remission of maternal depression: findings from the STAR*D-Child study. Am J Psychiatry 168: 593-602. [Crossref]

10. Post RM, Leverich GS, Kupka RW, Keck PE Jr, McElroy SL, et al. (2010) Early-onset bipolar disorder and treatment delay are risk factors for poor outcome in adulthood. $J$ Clin Psychiatry 71: 864-872. [Crossref]

11. Suominen, K, Mantere O, Valtonen H, Arvilommi P, Leppämäki S, et al. (2007) Early age at onset of bipolar disorder is associated with more severe clinical features but delayed treatment seeking. Bipolar Disord 9: 698-705. [Crossref]

12. Chengappa, KN, Kupfer DJ, Frank E, Houck PR, Grochocinski V, et al. (2003) Relationship of birth cohort and early age at onset of illness in a bipolar disorder case registry. Am J Psychiatry 160: 1636-1642. [Crossref]

13. Post RM, Kupka R, Keck PE Jr, McElroy SL, Altshuler LL, et al. (2016) Further Evidence of a Cohort Effect in Bipolar Disorder: More Early Onsets and Family History of Psychiatric Illness in More Recent Epochs. J Clin Psychiatry 77: 1043 1049. [Crossref]

14. Kessler RC, Angermeyer M, Anthony JC, Graaf RD, Demyttenaere K, et al. (2007) Lifetime prevalence and age-of-onset distributions of mental disorders in the World Health Organization's World Mental Health Survey Initiative. World Psychiatry 6: 168176. [Crossref]

15. Merikangas, He JP, Brody D, Fisher PW, Bourdon K, et al. ( 2010) Prevalence and treatment of mental disorders among US children in the 2001-2004 NHANES Pediatrics 125: 75-81. [Crossref]

16. Anderson LE, Perrin J M, Cleave JV (2015) Outpatient Visits and Medication Prescribing for US Children With Mental Health Conditions. Pediatrics 136: 11781185. [Crossref]

17. Post RM (2017) The New News About Lithium: An Underutilized Treatment in The United States. Neuropsychopharmacology. [Crossref]

18. Boyce WT (2014) The lifelong effects of early childhood adversity and toxic stress. Pediatr Dent 36: 102-108. [Crossref]

19. Hudziak J J, Albaugh MD, Ducharme S, Karama S, Spottswood M, et al. (2014) Cortical thickness maturation and duration of music training: health-promoting activities shape brain development. J Am Acad Child Adolesc Psychiatry 53: 1153-1161. [Crossref]

20. Miklowitz DJ, Chung B (2016) Family-Focused Therapy for Bipolar Disorder Reflections on 30 Years of Research. Fam Process 55: 483-499. [Crossref]

21. Miklowitz, DJ, Schneck CD, Singh MK, Taylor DO, George EL, et al. (2013) Early intervention for symptomatic youth at risk for bipolar disorder: a randomized trial of family-focused therapy. J Am Acad Child Adolesc Psychiatry: 121-131. [Crossref]

22. Post RM, Rowe M, Kaplan D, Findling RL (2017) A Multisymptomatic Child With Bipolar Disorder: How to Track and Sequence Treatment. Prim Care Companion CNS Disord 19. [Crossref]

23. Kowatch, R.A, Fristad M, Birmaher B, Wagner KD, Findling RL, et al. (2005) Treatment guidelines for children and adolescents with bipolar disorder. $J$ Am Acad Child Adolesc Psychiatry 44: 213-235. [Crossref]

24. Geller B, Tillman R, Bolhofner K, Zimerman B (2010) Pharmacological and non-drug treatment of child bipolar I disorder during prospective eight-year follow-up. Bipolar Disord 12: 164-171. [Crossref] 
25. Post RM, Kowatch RA (2006) The health care crisis of childhood-onset bipolar illness: some recommendations for its amelioration. J Clin Psychiatry 67: 115-125. [Crossref]

26. Post RM, Altshuler LL, Kupka R, McElroy SL, Frye MA, et al. (2016) More illness in offspring of bipolar patients from the U.S. compared to Europe. J Affect Disord 191: 180-186. [Crossref]

27. Geller B, Luby JL, Joshi P, Wagner KD, Emslie G, et al. (2012) A randomized controlled trial of risperidone, lithium, or divalproex sodium for initial treatment of bipolar I disorder, manic or mixed phase, in children and adolescents. Arch Gen Psychiatry 69: 515-528. [Crossref]

28. Kessing LV, Hansen HV, Hvenegaard A, Christensen EM, Dam H, et al.(2013) Treatment in a specialised out-patient mood disorder clinic v. standard out-patient treatment in the early course of bipolar disorder: randomised clinical trial. $\mathrm{Br} J$ Psychiatry 202: 212-219. [Crossref]
29. Kozicky JM, Torres IJ, Silveira LE, Bond DJ, Lam RW, et al. (2014) Cognitive change in the year after a first manic episode: association between clinical outcome and cognitive performance early in the course of bipolar I disorder. J Clin Psychiatry 75: 587-593. [Crossref]

30. Yatham LN, Mackala S, Basivireddy J, Ahn S, Walji N, et al. ( 2017 ) Lurasidone versus treatment as usual for cognitive impairment in euthymic patients with bipolar I disorder: a randomised, open-label, pilot study. Lancet Psychiatry 4: 208-217. [Crossref]

31. Berk M, Daglas R, Dandash O, Yücel M, Henry L, et al. ( 2017) Quetiapine v. lithium in the maintenance phase following a first episode of mania: randomised controlled trial. Br J Psychiatry 210: 413-421. [Crossref]

32. Post RM (2016) Epigenetic basis of sensitization to stress, affective episodes, and stimulants: implications for illness progression and prevention. Bipolar Disord 18 315-324. [Crossref]

Copyright: (02017 Post RM. This is an open-access article distributed under the terms of the Creative Commons Attribution License, which permits unrestricted use, distribution, and reproduction in any medium, provided the original author and source are credited. 